\title{
Corrigendum: Zebrafish Models of Craniofacial Malformations: Interactions of Environmental Factors
}

\author{
S. T. Raterman ${ }^{1,2,3}$, J. R. Metz ${ }^{3}$, Frank A. D. T. G. Wagener ${ }^{1,2}$ and \\ Johannes W. Von den Hoff ${ }^{1,2 *}$ \\ ${ }^{1}$ Radboud Institute of Molecular Life Sciences, Nijmegen, Netherlands, ${ }^{2}$ Department of Dentistry-Orthodontics and \\ Craniofacial Biology, Radboud University Medical Center, Nijmegen, Netherlands, ${ }^{3}$ Department of Animal Ecology and \\ Physiology, Institute for Water and Wetland Research, Radboud University, Nijmegen, Netherlands
}

Keywords: zebrafish, craniofacial malformations, neural crest cells, environment, gene, interaction

\section{A Corrigendum on}

Zebrafish Models of Craniofacial Malformations: Interactions of Environmental Factors by Raterman, S. T., Metz, J. R., Wagener, F. A. D. T. G., and Von den Hoff, J. W. (2020). Front. Cell

OPEN ACCESS

Edited by:

Erika Kuchler

University of Regensburg, Germany

Reviewed by:

Sabrina Kathrin Schulze,

University of Potsdam, Germany

${ }^{*}$ Correspondence:

Johannes W. Von den Hoff hans.vondenhoff@radboudumc.nl;

h.vondenhoff@dent.umcn.nl

Specialty section:

This article was submitted to

Cell Growth and Division,

a section of the journal

Frontiers in Cell and Developmental

Biology

Received: 08 January 2021

Accepted: 27 May 2021

Published: 24 June 2021

Citation:

Raterman ST, Metz JR,

Wagener FADTG and Von den Hoff JW (2021) Corrigendum: Zebrafish Models of Craniofacial

Malformations: Interactions of Environmental Factors.

Front. Cell Dev. Biol. 9:650948.

doi: 10.3389/fcell.2021.650948
Dev. Biol. 8:600926. doi: 10.3389/fcell.2020.600926

In the original article, there was an error. The error concerned reported exposure percentages.

A correction has been made to reported percentages in Alcohol, paragraph three:

"In search of ethanol sensitivity windows for craniofacial development, zebrafish embryos were exposed to a-rather extreme-regime of $10 \%$ ethanol during defined developmental stages (Ali et al., 2011). At 25 and $31 \mathrm{hpf}$ (developmental stages prim-6 and prim-16, respectively) embryos were most susceptible to defects of the branchial arches and Meckel's cartilage (Ali et al., 2011). Furthermore, in the late blastula and early gastrula stages, embryos appeared to be specifically sensitive for the induction of cyclopia after exposure to 2.4\% ethanol (Blader and Strahle, 1998). Upon chronic exposure, distinct craniofacial effects have been observed depending on ethanol dosage. Ethmoid plate development and head width were reduced at concentrations as low as $3 \mathrm{mM}$ $(0.01 \%)$, which can be reached in women upon drinking only one alcoholic beverage (Carvan et al., 2004; Ferdous et al., 2017). Interestingly, with rising concentrations, a sensitivity shift was reported. At $10 \mathrm{mM}$ ethanol (0.04\%), neurocranium structures were more severely affected than structures of the viscerocranium, while at $30 \mathrm{mM}(0.13 \%)$ the opposite was observed (Carvan et al., 2004). Variations in sensitivity to ethanol exposure between zebrafish strains are also reported. Upon exposure, Ekkwill strain zebrafish presented with a severely affected viscerocranium and increased apoptosis, whereas $\mathrm{AB}$ strain zebrafish had affected neurocranial cartilages such as the ethmoid plate. In Tübingen strain zebrafish larvae a high mortality rate was observed, but this strain was less prone to craniofacial defects (Loucks and Carvan, 2004). The strain specific sensitivity to ethanol implicates that predisposing genetic factors and GxE interactions are involved."

A correction has been made to reported percentages in Vitamins and ExE Interactions, Vitamin A, paragraph four:

"Epidemiological studies showed that the risk of FASD and craniofacial malformation were higher in pregnancies with alcohol exposure in low socioeconomic environments. In these environments, maternal malnutrition and vitamin (A) deficiency are more frequent (Jiang et al., 2020). Ethanol competes with retinol for a dehydrogenase that converts retinol into RA and ethanol into acetaldehyde (Marrs et al., 2010). In zebrafish, RA and ethanol appear to exert opposing effects 
on ethmoid plate development. Zebrafish larvae treated with $100 \mathrm{mM}(0.6 \%)$ ethanol showed a reduced ethmoid plate width, which was rescued by a low dose $(1 \mathrm{nM})$ of exogenous RA. In the same study, RA addition without alcohol exposure resulted in a wider ethmoid plate (Marrs et al., 2010). Disruption of

\section{REFERENCES}

Ali, S., Champagne, D. L., Alia, A., and Richardson, M. K. (2011). Large-scale analysis of acute ethanol exposure in zebrafish development: a critical time window and resilience. PLoS One 6:e20037. doi: 10.1371/journal.pone.0020037

Blader, P., and Strahle, U. (1998). Ethanol impairs migration of the prechordal plate in the zebrafish embryo. Dev. Biol. 201, 185-201. doi: 10.1006/dbio.1998.8995

Carvan, M. J. III., Loucks, E., Weber, D. N., and Williams, F. E. (2004). Ethanol effects on the developing zebrafish: neurobehavior and skeletal morphogenesis. Neurotoxicol. Teratol. 26, 757-768. doi: 10.1016/j.ntt.2004.0 6.016

Ferdous, J., Mukherjee, R., Ahmed, K. T., and Ali, D. W. (2017). Retinoic acid prevents synaptic deficiencies induced by alcohol exposure during gastrulation in zebrafish embryos. Neurotoxicology 62, 100-110. doi: 10.1016/j.neuro.2017. 05.01

Jiang, Q., Lu, D., Wang, F., Zhang, Y., Cao, L., Gui, Y., et al. (2020). Folic acid supplement rescues ethanol-induced developmental defects in the
RA signaling appears to be a distinct mechanism of alcohol teratogenesis and is an example of an ExE interaction."

The authors apologize for these errors and state that this does not change the scientific conclusions of the article in any way. The original article has been updated.

zebrafish embryos. Acta Biochim. Biophys. Sin. 52, 536-545. doi: 10.1093/abbs/ gmaa030

Loucks, E., and Carvan, M. J. I. I. I. (2004). Strain-dependent effects of developmental ethanol exposure in zebrafish. Neurotoxicol. Teratol. 26, 745-755. doi: 10.1016/j.ntt.2004.06.017

Marrs, J. A., Clendenon, S. G., Ratcliffe, D. R., Fielding, S. M., Liu, Q. and Bosron, W. F. (2010). Zebrafish fetal alcohol syndrome model: effects of ethanol are rescued by retinoic acid supplement. Alcohol 44, 707-715. doi: 10.1016/j.alcohol.2009.03.004

Copyright (c) 2021 Raterman, Metz, Wagener and Von den Hoff. This is an openaccess article distributed under the terms of the Creative Commons Attribution License (CC BY). The use, distribution or reproduction in other forums is permitted, provided the original author(s) and the copyright owner(s) are credited and that the original publication in this journal is cited, in accordance with accepted academic practice. No use, distribution or reproduction is permitted which does not comply with these terms. 